Research Article

\title{
Risk Assessment for Corneal Ectasia following Photorefractive Keratectomy
}

\author{
Nir Sorkin, ${ }^{1,2}$ Igor Kaiserman, ${ }^{2,3,4}$ Yuval Domniz, ${ }^{2}$ Tzahi Sela, ${ }^{2}$ Gur Munzer, ${ }^{2}$ and \\ David Varssano ${ }^{1}$
}

${ }^{1}$ Department of Ophthalmology, Tel Aviv Sourasky Medical Center, Affiliated to the Sackler School of Medicine, Tel Aviv University, Tel Aviv, Israel

${ }^{2}$ Care Laser Inc., Tel Aviv, Israel

${ }^{3}$ Department of Ophthalmology, Barzilai Medical Center, Ashkelon, Israel

${ }^{4}$ Faculty of Health Sciences, Ben-Gurion University of the Negev, Beersheba, Israel

Correspondence should be addressed to Nir Sorkin; nir_sorkin@yahoo.com

Received 14 January 2017; Revised 11 April 2017; Accepted 26 April 2017; Published 26 July 2017

Academic Editor: Antonio Queiros

Copyright (C) 2017 Nir Sorkin et al. This is an open access article distributed under the Creative Commons Attribution License, which permits unrestricted use, distribution, and reproduction in any medium, provided the original work is properly cited.

Purpose. To analyze the risk factors associated with a series of ectasia cases following photorefractive keratectomy (PRK) and all published cases. Methods. In a retrospective study on post-PRK ectasia patients, 9 eyes of 7 patients were included, in addition to 20 eyes of 13 patients from the literature. Risk of post-PRK ectasia was calculated using the ectasia risk score system (ERSS) for laser in situ keratomileusis (LASIK) patients. The percent tissue altered (PTA) was also evaluated. Results. ERSS scoring of zero for age, RSB, and spherical equivalent was found in $66 \%, 86 \%$, and $86 \%$ of the eyes, respectively. Pachymetry risk score was 2 in $60 \%$ of the eyes and 3 or 4 in 16\% of the eyes. Topography risk score was 3 in $41 \%$ of the eyes and 4 in $21 \%$ of the eyes. Cumulative ectasia risk score was $\geq 4$ (high risk) in $77 \%$ of the eyes and $\geq 3$ (medium and high risk) in $86 \%$ of the eyes. Average PTA was $23.2 \pm 7.0 \%$. All eyes but one had a PTA $<40 \%$. Conclusions. Preoperative corneal topographic abnormalities and thin corneas may be significant risk factors for developing ectasia following PRK. Post-LASIK ectasia risk scoring also has relevance in the risk for developing post-PRK ectasia.

\section{Introduction}

Corneal ectasia is a well-recognized, serious complication of laser in situ keratomileusis (LASIK) [1]. It is characterized by progressive stromal thinning and steepening of the cornea, resulting in refractive aberrations and vision loss. The incidence in LASIK patients is estimated to be between $0.04 \%$ and $0.6 \%$ [1]. Ectasia following PRK is considered extremely rare and has been described previously in only a few case reports [2-8] and small case series [9-12].

The risk for developing post-LASIK ectasia is routinely assessed prior to surgery and includes evaluation of patient age, degree of refractive correction, topographic findings, corneal pachymetry, and residual stromal bed (RSB). In 2008, Randleman et al. [13] proposed an ectasia risk score system (ERSS) for evaluating post-LASIK ectasia risk [13] and later validated it in a second study [14]. More recently, the value of percent tissue altered (PTA) was found to be a robust indicator of the risk for post-LASIK ectasia $[15,16]$. Due to the paucity of post-PRK ectasia cases, there is no corresponding system for evaluating its risk of occurrence.

In this study, risk factors for development of post-PRK ectasia were analyzed in a series of post-PRK ectasia cases, and in all post-PRK ectasia cases found in the literature.

\section{Materials and Methods}

This retrospective cohort study of post-PRK corneal ectasia patients was approved by the Institutional Review Board of the Tel Aviv Sourasky Medical Center, Tel Aviv, Israel, and followed the tenets of the Declaration of Helsinki. 
TABLE 1: The ectasia risk score system (ERSS) for ectasia following LASIK ${ }^{\mathrm{a}}$ [13].

\begin{tabular}{|c|c|c|c|c|c|}
\hline \multirow{2}{*}{ Parameter } & \multicolumn{5}{|c|}{ Points } \\
\hline & 4 & 3 & 2 & 1 & 0 \\
\hline Topography & FFKC $^{\mathrm{b}}$ & Inf. steep. ${ }^{c}$ & - & $\mathrm{ABT}^{\mathrm{d}}$ & Normal/SBT ${ }^{\mathrm{e}}$ \\
\hline $\operatorname{RSB}^{\mathrm{f}}(\mu \mathrm{m})$ & $<240$ & 240 to 259 & 260 to 279 & 280 to 299 & $>300$ \\
\hline Age (years) & - & 18 to 21 & 22 to 25 & 26 to 29 & $>30$ \\
\hline Pachymetry $(\mu \mathrm{m})$ & $<450$ & 451 to 480 & 481 to 510 & - & $>510$ \\
\hline $\mathrm{SEQ}^{\mathrm{g}}(\mathrm{D})$ & $>-14$ & $>-12$ to -14 & $>-10$ to -12 & $>-8$ to -10 & $\leq-8$ \\
\hline & & $\begin{array}{l}\text { Low } \\
\text { Moder } \\
\text { High }\end{array}$ & $\begin{array}{l}\text { oints } \\
\text { points } \\
\text { oints }\end{array}$ & & \\
\hline
\end{tabular}

${ }^{a}$ Laser-assisted in situ keratomileusis; ${ }^{b}$ forme fruste keratoconus; ${ }^{c}$ inferior steepening; ${ }^{\mathrm{d}}$ asymmetric bowtie; ${ }^{\mathrm{e}}$ symmetric bowtie; ${ }^{\mathrm{f}}$ residual stromal bed; ${ }^{\mathrm{g}}$ manifest refraction spherical equivalent.

2.1. Patients. Cases that were 18 years and older with a history of PRK and a diagnosis of corneal ectasia were included in the study. None had any previous ocular pathology or relevant ocular or familial history. Our series consisted of 9 eyes of 7 patients (study cohort) who developed post-PRK ectasia, out of 31,045 eyes $(0.029 \%)$ who underwent PRK during the same time period (2004-2015). There were 4 males and 3 females, mean age $26 \pm 8.2$ years (range 18-39 years), 5 right eyes and 4 left eyes. The 8 papers [5-12], published between 2000 and 2008, which were included in the literature analysis, reported a total of 20 eyes of 13 patients with post-PRK ectasia (literature search eyes).

2.2. Methods. Data were collected from the electronic medical database of Care Vision, a refractive surgery facility in Tel Aviv, Israel. The diagnosis of post-PRK ectasia was verified by a cornea surgeon (DV). Ectasia was defined as progressive steepening of the central or mid-lower cornea, and/or progressive thinning of the central or mid-lower cornea. When evaluating for ectasia, the examiner (DV) took into account changes in manifest refraction, keratometry, pachymetry, inferior-superior differences, location of the thinnest point and steepest point, and posterior elevation (thinnest point and posterior elevation were available in cases where Scheimpflug or slit-scanning tomography had been performed). Topography was obtained from the TMS (Tomey, Tennenlohe, Germany), Orbscan (Bausch \& Lomb, Rochester, NY, USA), Topolyzer (Oculus, Wetzlar, Germany), and Sirius (C.S.O., Florence, Italy). Preoperative pachymetry was obtained using ultrasound, Orbscan (Bausch \& Lomb, Rochester, NY, USA), or Sirius (C.S.O., Florence, Italy). RSB was calculated based on the formula

$$
\begin{aligned}
\mathrm{RSB}= & \text { preoperative pachymetry }- \text { ablation depth } \\
& -50 \mu \mathrm{m}(\text { estimated epithelial thickness }) .
\end{aligned}
$$

2.3. Main Outcome Measures. The following data were recorded and assessed: patient demographics; ocular and familial history; preoperative data including best spectaclecorrected visual acuity (BSCVA), manifest refraction, pachymetry and topography; and perioperative and postoperative data including ablation depth, RSB (calculated), number of enhancement procedures, and the time from PRK until the appearance of ectasia.

A systematic search of the literature was carried out on August 25, 2015, using the PubMed search engine and the search terms (Photorefractive Keratectomy OR PRK) AND ectasia. All case reports and case series that had data on topography, and either RSB, pachymetry, or refractive error, were included. Cases without topography data were excluded. In cases where topography images were available, the diagnosis of post-PRK ectasia was verified by a cornea surgeon (DV). In cases where topography data was available without topography images, the data was recorded as detailed by that paper's author. The same patient data, as detailed above, were collected from all published cases, where present (in cases where partial data was available, only the available data was recorded).

There were 15 papers in the literature describing post-PRK ectasia: 7 case reports [2-8], 4 case series [9-12], and 4 large series composed mainly of post-LASIK ectasia patients and 1 to 3 post-PRK ectasia patients in each [17-20]. The 4 large post-LASIK series that included a few post-PRK patients did not present separate data on the post-PRK eyes and therefore were not included in the analysis. Three of the case reports [2-4] did not include preoperative topography data and were therefore excluded. One case series [11] only had topography data for 2 of 8 eyes, and therefore, only those 2 eyes were included. The 8 papers that were included reported a total of 20 eyes of 13 patients: 7 eyes of 4 patients in 7 case reports and 13 eyes of 9 patients in 4 case series.

Risk factors for ectasia following PRK were those of the ERSS (Table 1) [13] and the calculated PTA $[15,16]$.

PTA for PRK was calculated based on the formula

$$
\text { PTA }=\frac{\text { (ablation depth }+50 \mu \mathrm{m} \text { for epithelial thickness })}{\text { preoperative pachymetry }} .
$$

\section{Results}

In our series, there were 9 eyes of 7 patients. Refractive error was low to moderate (SEQ range -0.75 to $-3.88 \mathrm{D}$ ). None of the patients had any refractive enhancements following the PRK procedure. All 9 eyes had abnormal preoperative topographic patterns, according to the ERSS system [13], 
including asymmetric bowtie (ABT), skewed radial axis (SRAX), or abnormal inferior-superior value (I-S). Two of 7 patients developed bilateral ectasia and 5 of 7 patients developed unilateral ectasia. In the patients who developed unilateral ectasia, preoperative topography of the fellow eyes also showed topographic abnormalities, including two eyes with ABT (case numbers 2 and 7), two eyes with SRAX (case numbers 1 and 6), and one eye with I-S value of 1.5 (case number 3). Pachymetry prior to surgery was below $500 \mu \mathrm{m}$ in 3 of the eyes. Maximal ablation depth was $52 \pm 18 \mu \mathrm{m}$ (range 23-74). Calculated RSB was below $400 \mu \mathrm{m}$ in 3 of the eyes. Demographic, preoperative, and postoperative data of our series are shown in Table 2. Figure 1 shows the preoperative (Figure 1(a)) and postectasia (Figure 1(b)) topography of one of the patients (case number 7 in Table 2).

Ectasia was diagnosed 27.2 \pm 12.4 months (range 3.3-45) following surgery. Ectasia was diagnosed earlier than 12 months following PRK in one eye. At the time of ectasia diagnosis, all eyes that had preoperative posterior corneal elevation values showed substantial increase of those values from $32 \pm 7 \mu \mathrm{m}$ (range 22-40) to $51 \pm 15 \mu \mathrm{m}$ (range 31-79) (Table 2). In addition, 8 of 9 eyes had substantial progression of inferior steepening, as demonstrated by the increase in I-S values (Table 2). One eye had no change in I-S value, but had progression of posterior corneal elevation with an inferior displacement of the posterior elevation apex (case number 3 , Table 2). Only 1 of 9 eyes showed substantial alterations in manifest refraction and BSCVA at the time of ectasia diagnosis (Case no. 7, Table 2). Central keratometric values did not show a substantial change at the time of ectasia diagnosis. Following the diagnosis of ectasia, 5 of 9 eyes underwent corneal crosslinking and had no progression during the remaining follow-up. Four of 9 eyes were monitored and showed no evidence of progression. None of the eyes required keratoplasty.

Table 3 summarizes the demographic, preoperative, and postoperative data of the 20 literature search eyes that were included in the analysis.

The risk factors for the development of ectasia in all eyes, including the study eyes and the published cases found in the literature search, were analyzed using the ERSS criteria [13] and are summarized in Table 4.

The distribution of all eyes (including eyes from the study cohort and eyes from the literature search) by risk groups is presented in Figure 2 and Table 5.

The mean cumulative ectasia risk score was $5.5 \pm 2.3$, with a range of 1 to 10 of 19 possible points. Cumulative ectasia risk score of 4 or greater, defined as high risk [13], was present in $77 \%$ of the eyes; $14 \%$ of the eyes were classified as low risk ( 2 points or less), and $9 \%$ as moderate risk (3 points). The distribution of the cumulative risk scores (for all eyes, including the study cohort and eyes from the literature search) is presented in Figure 3.

PTA was $20.1 \pm 3.4 \%$ (range 14.6-25.2) in the study cohort, and $26.6 \pm 7.7 \%$ (range 16.2-40.3) in the literature search eyes. PTA of all eyes was $23.2 \pm 7.0 \%$ (range 14.640.3). All eyes had a PTA $<40 \%$, except for one literaturesearch eye with a PTA of $40.3 \%$.

\section{Discussion}

Post-PRK ectasia is much less prevalent than post-LASIK ectasia. In the study cohort, the rate of post-PRK ectasia was 9 out of 31,045 eyes $(0.029 \%)$ who underwent PRK during the same period. This is compared with $0.1 \%$ to $0.66 \%$ reported following LASIK [1].

Ectasia was diagnosed postoperatively at $27.2 \pm 12.4$ months (range 3.3-44.8) in our cohort. Data in the literature on post-LASIK ectasia show ectasia diagnosis as early as 1 week and as late as 48 months [13]. However, most cases of post-LASIK ectasia are diagnosed during the first year [13]. In our series, only one eye (11\%) had been diagnosed with post-PRK ectasia during the first postoperative year. Among the literature search eyes, 8 of $20(40 \%)$ have been diagnosed during the first year. Altogether, the rate of first-year ectasia diagnosis in PRK patients was 31\%. This may indicate that post-PRK ectasia is diagnosed later than post-LASIK ectasia, although this cannot be determined conclusively, due to the small sample size of post-PRK ectasia cases and the large variability of diagnosis time.

At the time of ectasia diagnosis, most of the patients ( 8 of 9 eyes) had no substantial change in central keratometry, manifest refraction, or BSCVA, despite having significant topographic changes, as evident in the increase in I-S values. This indicates early-stage diagnosis that was made during routine follow-up, while the patients were still asymptomatic. Therefore, it may be important to maintain long-term annual follow-up of PRK patients. None of the eyes in our cohort required keratoplasty. All cases were managed by either crosslinking or monitoring for progression. Both options should be considered in such cases. The initial choice of management should be based on the degree of refractive and topographic progression, and ongoing monitoring may be crucial.

In their validation of the ERSS criteria, Randleman et al. [14] reevaluated the 5 risk factors for ectasia following LASIK: abnormal preoperative topographic patterns, low RSB thickness, young age, low preoperative corneal pachymetry, and high myopia. In their study, abnormal preoperative topography was the most significant risk factor: $59.6 \%$ of the eyes had a score of $3(14.7 \%)$ or 4 (44.9\%). In our study, $62.1 \%$ of the eyes had a topography score of $3(41.4 \%)$ or $4(20.7 \%)$, documenting a dominance of suspicious abnormal preoperative topographic patterns in post-PRK ectasia patients.

In Randleman's analysis, RSB was the next risk factor in order of significance. Eighty-six percent of our post-PRK patients had RSB scores of zero in contrast to the $31.6 \%$ in Randleman's analysis. This difference may be a direct result of the lack of a stromal flap in PRK, which results in thicker RSB. Thus, the RSB score of the ERSS may not be relevant in PRK patients.

The age and SEQ scores of zero (65.6\% and $86.2 \%$, resp.) in the vast majority of the study cohort may indicate less influence of those factors on the risk of ectasia. These values are very similar to those reported in the validation study of the ERSS criteria [14], in which age and SEQ score of zero were found in $68.4 \%$ and $72.8 \%$ of the patients, respectively. 


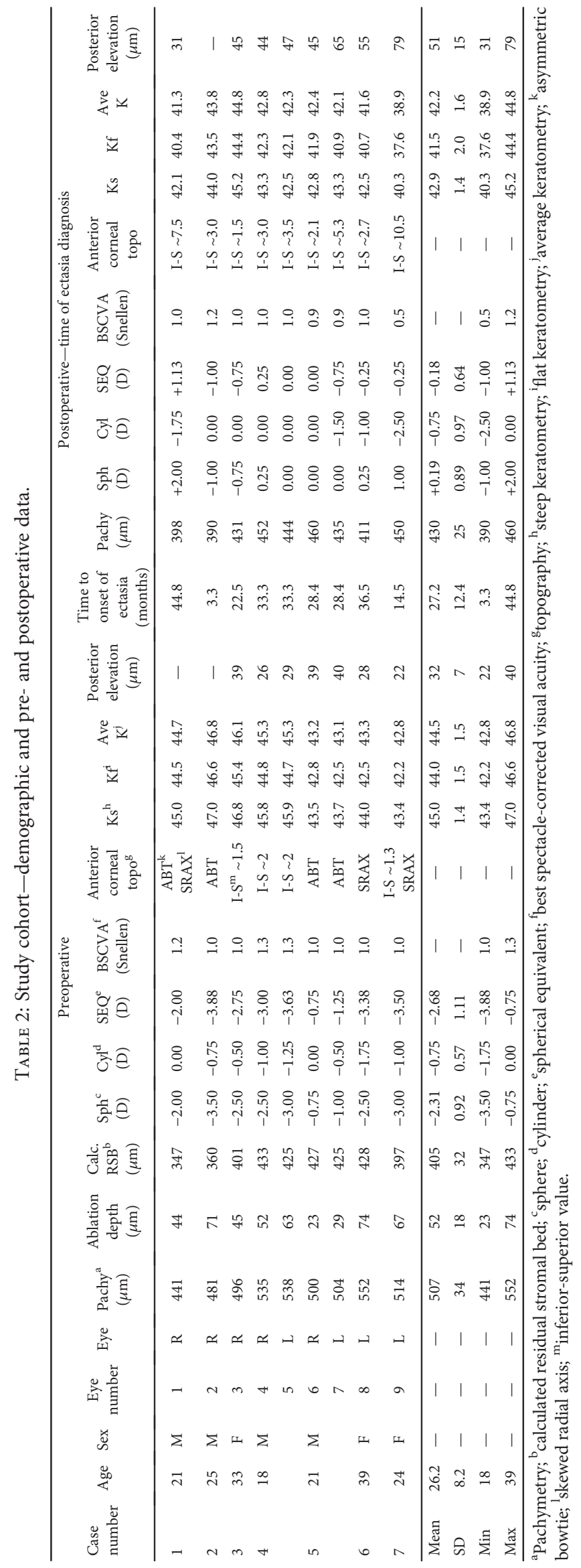




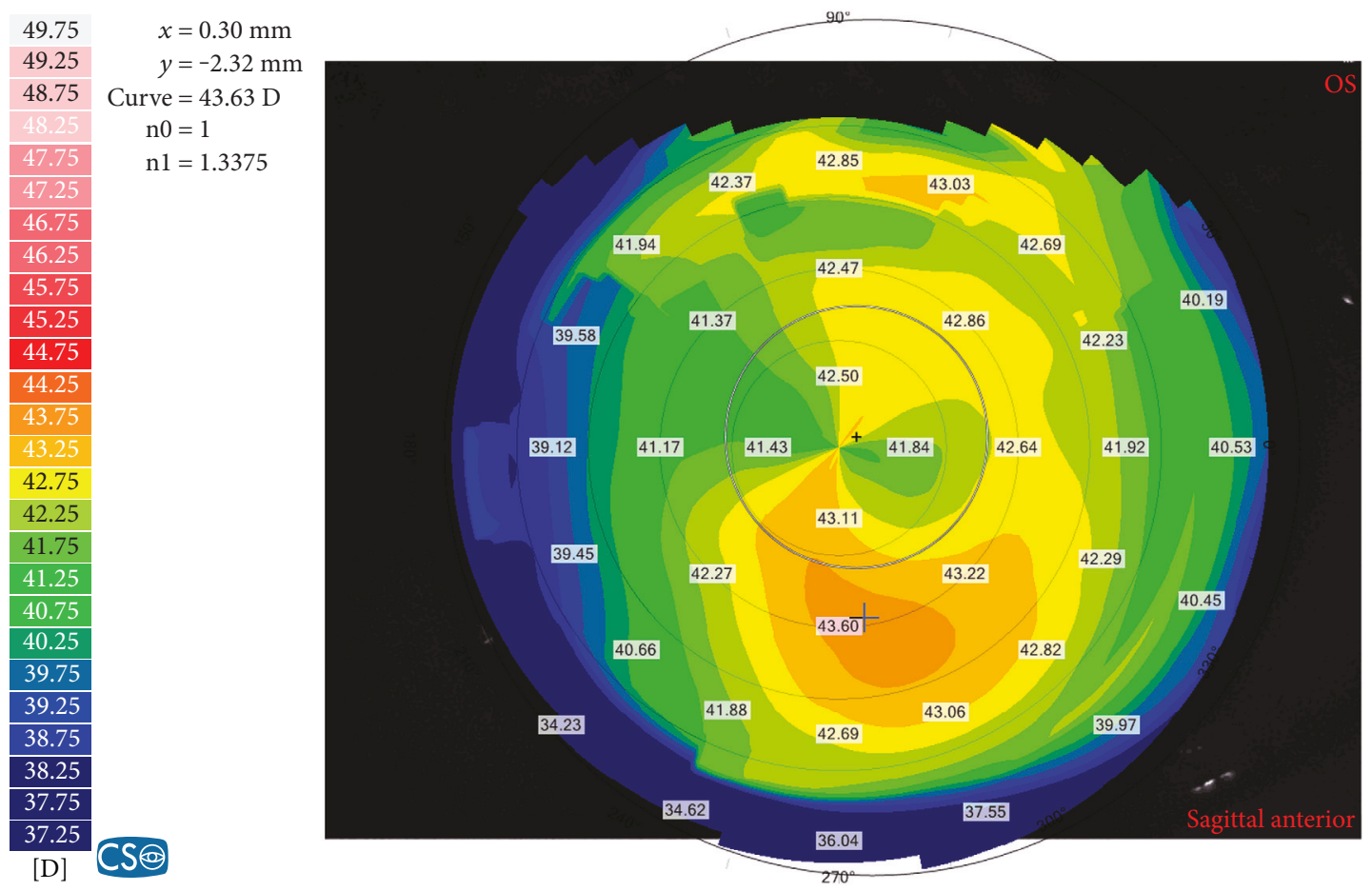

(a)

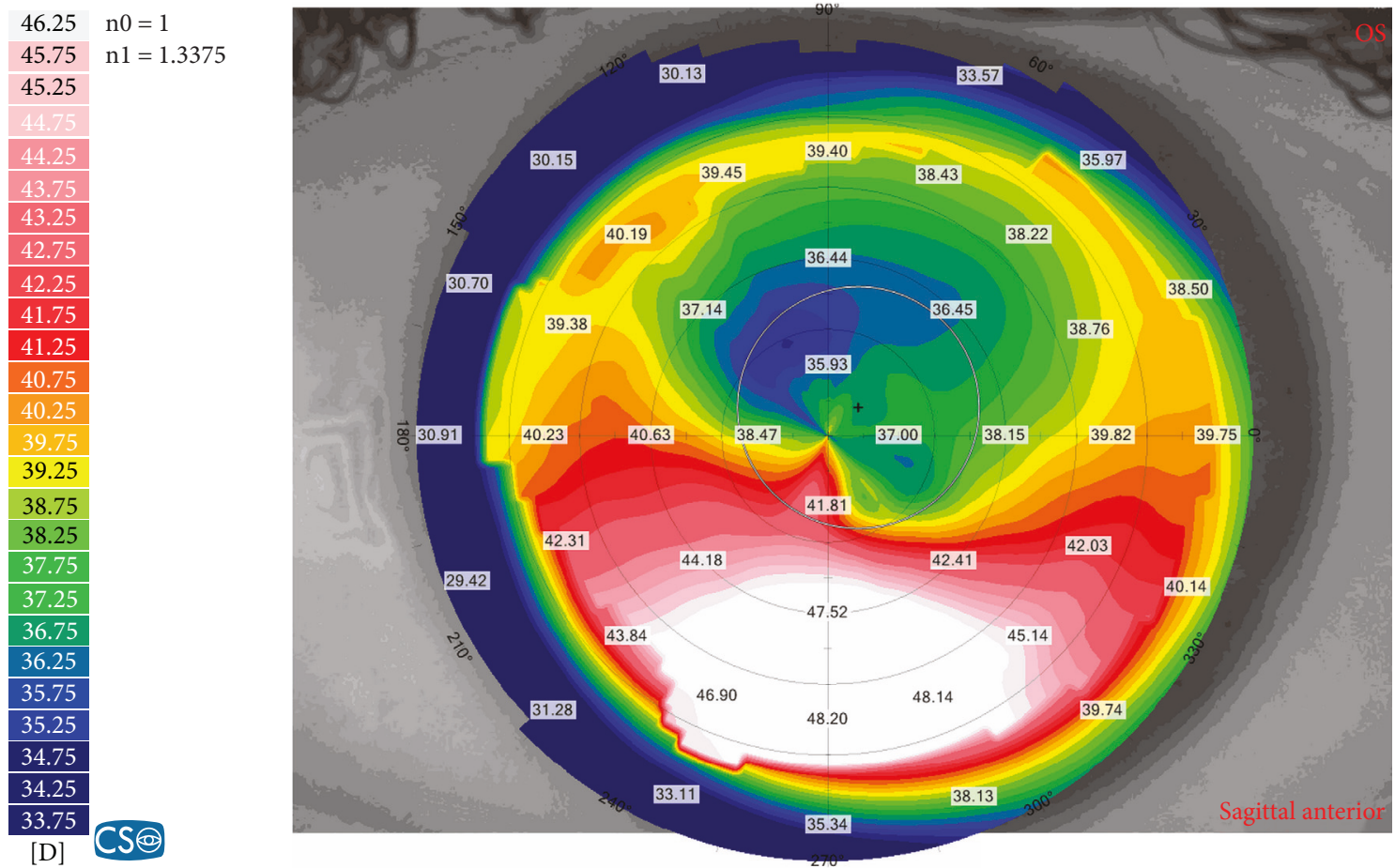

(b)

FIgURE 1: The preoperative (a) and post-ectasia (b) topographies of case number 7 in Table 2.

Preoperative corneal thickness was the least significant risk factor in the ERSS [13], but significant in our study: $60.0 \%$ had a score of 2 (low risk) and $16.0 \%$ had a score of either 3 (medium risk) or 4 (high risk). These scores may signify the importance of preoperative corneal thickness in the evaluation of the risk for post-PRK ectasia.
The majority (77\%) of eyes included in the analysis were at high risk for ectasia according to the ERSS. In the initial ERSS publication containing the original scoring system, 92.6\% of post-LASIK ectasia eyes were at high risk. Thus, using ERSS to evaluate risk for posttreatment ectasia in PRK may have value. 


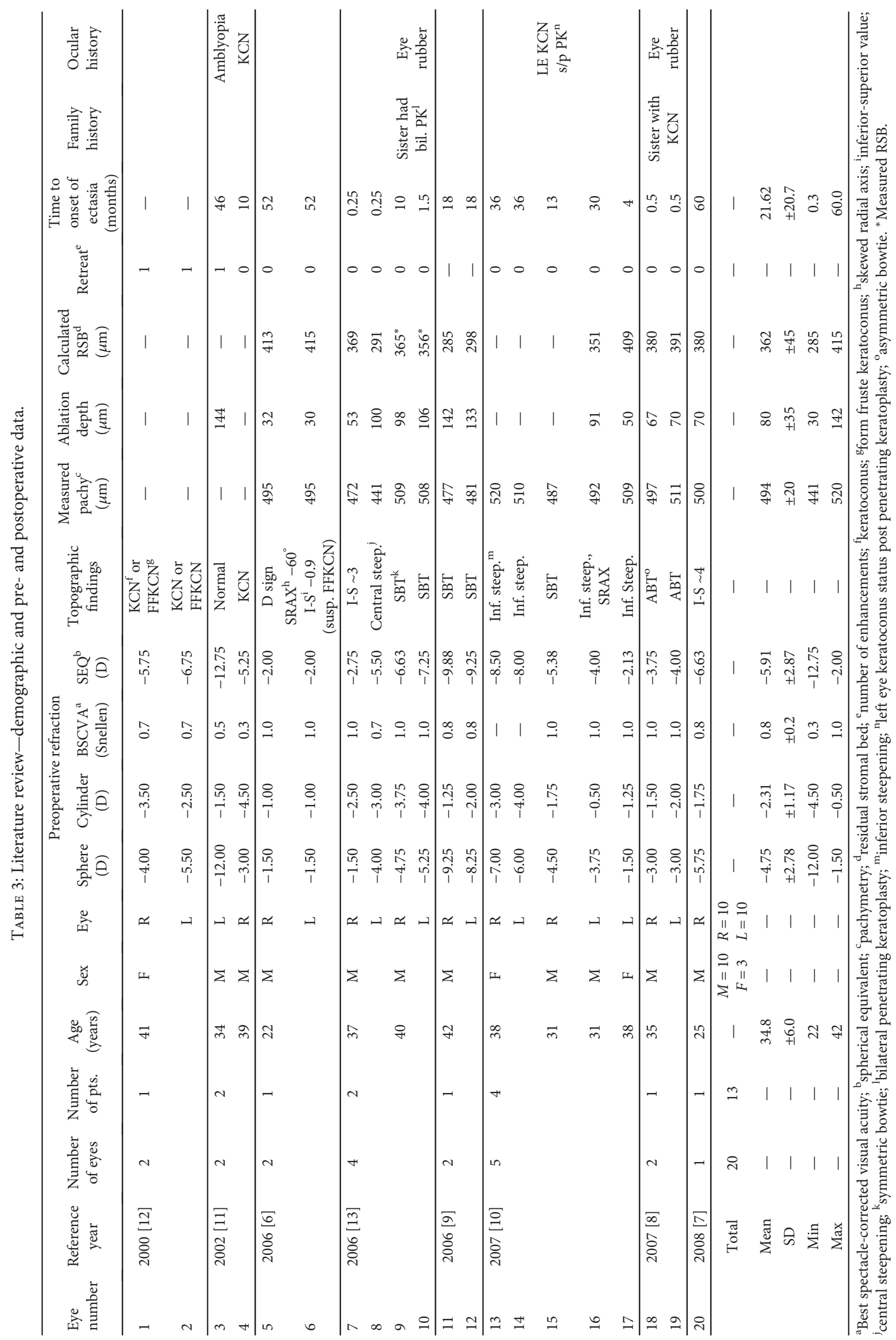




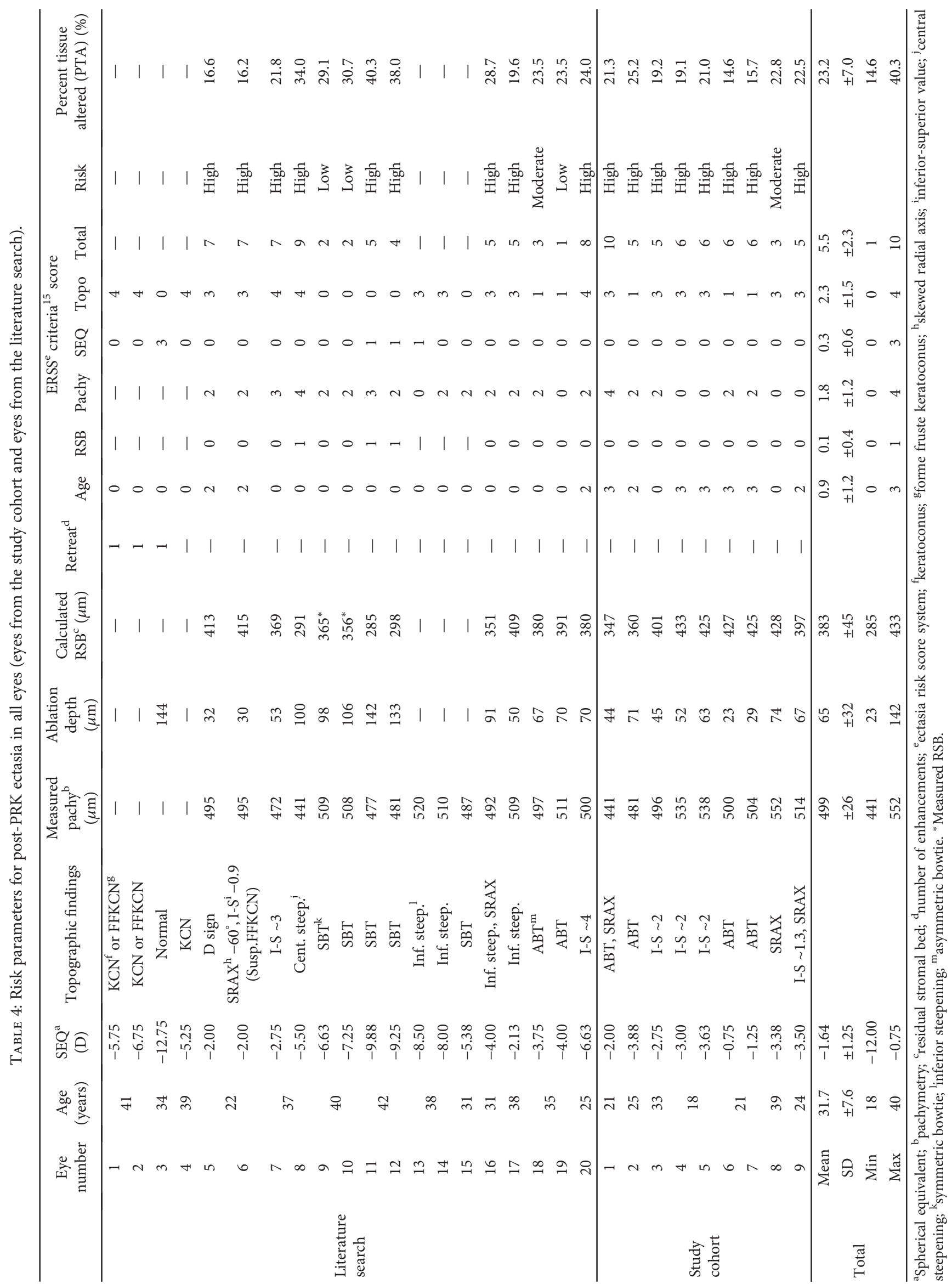




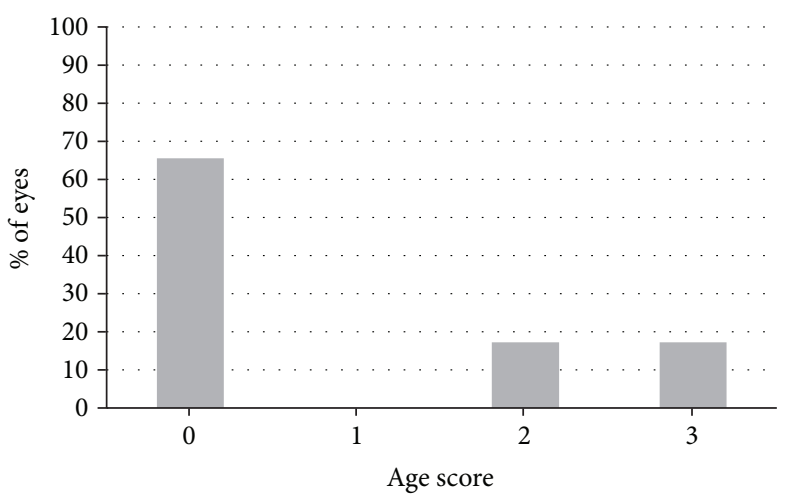

(a)

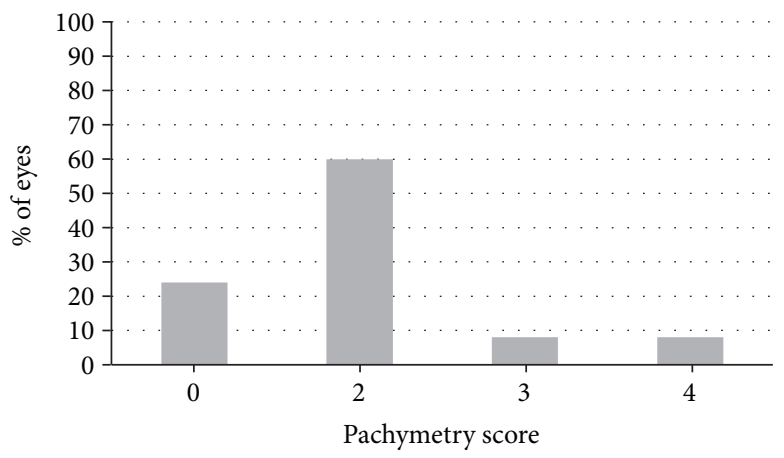

(c)

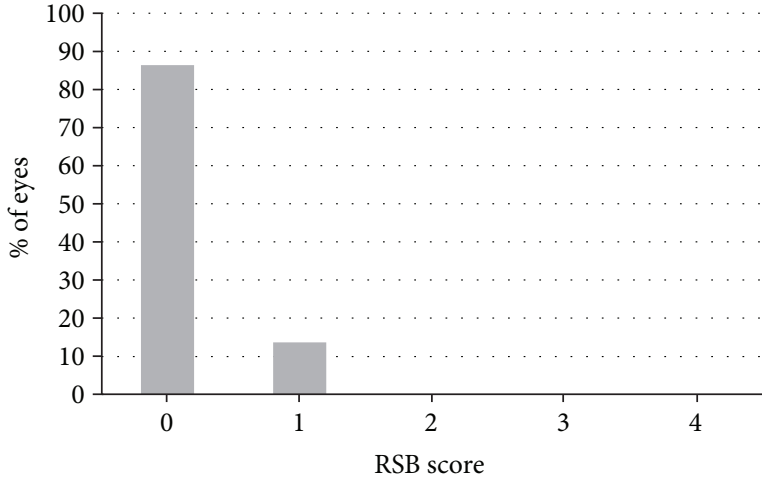

(b)

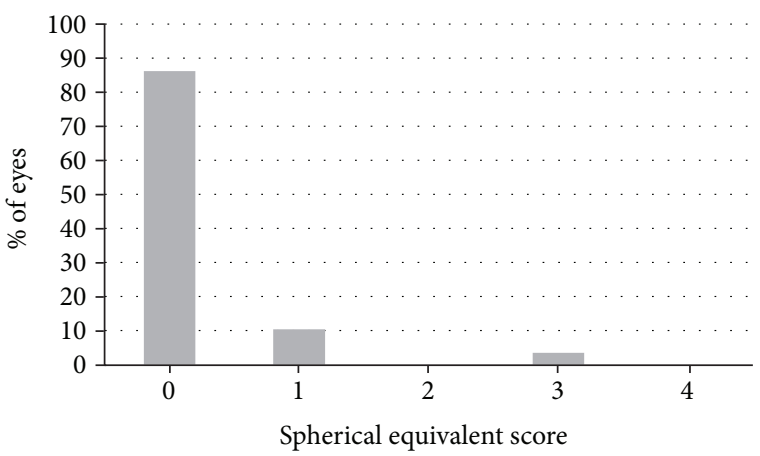

(d)

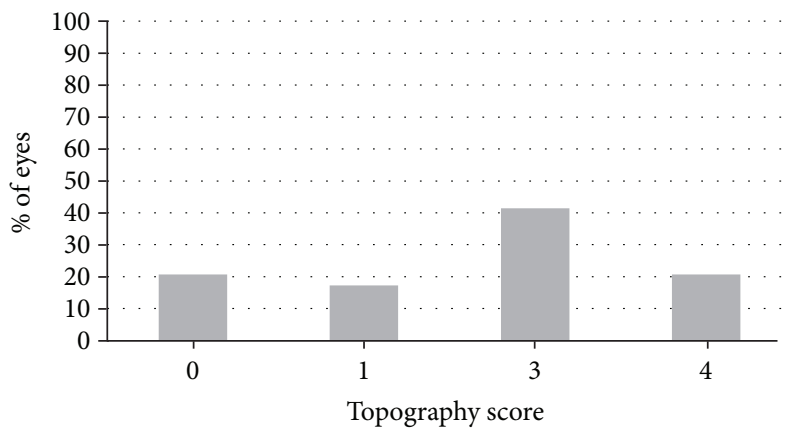

(e)

FIgURE 2: Distribution of the eyes by risk groups (included were eyes from the study cohort and eyes from the literature search): (a) age, (b) residual stromal bed (RSB), (c) pachymetry, (d) spherical equivalent, (e) topography.

TABle 5: The distribution of eyes according to ectasia risk score system (ERSS) scores for each risk parameter.

\begin{tabular}{lcccccc}
\hline \multirow{2}{*}{ Parameter } & & 4 & 3 & 2 & 1 & 0 \\
\hline Topography & $(n=29)$ & $20.7 \%$ & $41.4 \%$ & & $17.2 \%$ & $20.7 \%$ \\
RSB $^{\mathrm{a}}$ & $(n=22)^{*}$ & $0 \%$ & $0 \%$ & $0 \%$ & $13.6 \%$ & $86.4 \%$ \\
Age & $(n=29)$ & & $17.2 \%$ & $17.2 \%$ & 0 & $65.6 \%$ \\
Pachymetry & $(n=25)^{*}$ & $8.0 \%$ & $8.0 \%$ & $60.0 \%$ & & $24.0 \%$ \\
SEQ $^{\mathrm{b}}$ & $(n=29)$ & $0 \%$ & $3.5 \%$ & $0 \%$ & $10.3 \%$ & $86.2 \%$ \\
\hline
\end{tabular}

${ }^{a}$ Residual stromal bed; ${ }^{b}$ manifest refraction spherical equivalent; ${ }^{*}$ included in this analysis were eyes that had available data for the specific parameter tested.

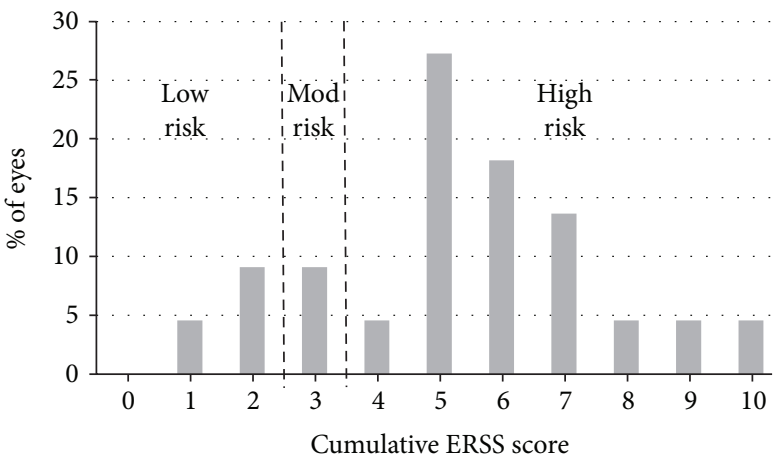

FIgURE 3: Distribution of the cumulative ectasia risk scores. Included in the analysis were 22 eyes (from the study cohort and from the literature search) that had available data for all ERSS (ectasia risk score system) parameters. 
Average PTA was low at $23.2 \pm 7.0 \%$. Lower PTA values are expected following PRK, since there is no creation of a LASIK flap and therefore less manipulation of the anterior stroma. Regarding PRK, there is no data as of yet regarding the PTA threshold that may indicate higher risk for postPRK ectasia. In eyes with normal preoperative topographies, PTA $\geq 40 \%$ was previously found to be a substantial risk factor for post-LASIK ectasia [15]. A study on post-LASIK ectasia eyes compared average PTA values between eyes with normal, low-suspect, and high-suspect preoperative topographies. The results showed average PTA of 45,39 , and $36 \%$ in each of the groups, respectively [16]. This leads to the conclusion that in eyes with preoperative topographic abnormalities, less manipulation of stroma is needed to induce ectasia. Only two eyes (both in the literature search group) had a PTA higher than $36 \%$ (values of $38.0 \%$ and $40.3 \%$ ). This may indicate that high-risk topographic abnormalities are more indicative of post-PRK ectasia risk than PTA.

There are certain limitations to this study. Because this was a retrospective study and because post-PRK ectasia is rare, the data available were limited, which limited the number of cases that could be analyzed. Not all required data was available for the literature eyes. Also, since the period that was evaluated spanned 15 years, measurements (such as pachymetry, keratometry, and topography) were obtained by different devices. This affects the accuracy of comparison. The geographic distribution of included post-PRK ectasia cases probably does not properly represent the true global distribution of post-PRK ectasia due to a probable under-reporting of post-PRK ectasia worldwide. The presence of a large group originating from a single center may reflect local factors that cannot be well extrapolated to PRK candidates elsewhere.

In conclusion, while there is similarity between the risk factors for ectasia following LASIK and PRK, the factors differ in importance for each of the procedures. The findings demonstrate that ERSS, the risk score system developed and validated for LASIK, may have value in PRK ectasia risk evaluation. This emphasizes the need for a dedicated scoring system in PRK, despite the rarity of ectasia following PRK. It goes without saying that until such a scoring system is developed, increased caution must be exercised when abnormal values exist.

\section{Conflicts of Interest}

The authors declare that they have no conflict of interest.

\section{Acknowledgments}

This manuscript is derived from a paper presentation at the American Society of Cataract and Refractive Surgeons (ASCRS) Annual Meeting, 2015, San Diego, CA, USA.

\section{References}

[1] M. R. Santhiago, N. T. Giacomin, D. Smadja, and S. J. Bechara, "Ectasia risk factors in refractive surgery," Clinical Ophthalmology, vol. 10, pp. 713-720, 2016.
[2] K. Miyata, T. Takahashi, A. Tomidokoro, K. Ono, and T. Oshika, "Iatrogenic keratectasia after phototherapeutic keratectomy," The British Journal of Ophthalmology, vol. 85, no. 2, pp. 247-248, 2001, England.

[3] D. Parmar and C. Claoue, "Keratectasia following excimer laser photorefractive keratectomy," Acta Ophthalmologica Scandinavica, vol. 82, no. 1, pp. 102-105, 2004.

[4] H. Kim, J. S. Choi, and C. K. Joo, "Corneal ectasia after PRK: clinicopathologic case report," Cornea, vol. 25, no. 7, pp. 845-848, 2006.

[5] F. Malecaze, J. Coullet, P. Calvas, P. Fournié, J. L. Arné, and C. Brodaty, "Corneal ectasia after photorefractive keratectomy for low myopia," Ophthalmology, vol. 113, no. 5, pp. 742746, 2006

[6] J. Reznik, J. J. Salz, and A. Klimava, "Development of unilateral corneal ectasia after PRK with ipsilateral preoperative forme fruste keratoconus," Journal of Refractive Surgery, vol. 24, no. 8, pp. 843-847, 2008.

[7] A. Navas, E. Ariza, A. Haber, S. Fermón, R. Velázquez, and R. Suárez, "Bilateral keratectasia after photorefractive keratectomy," Journal of Refractive Surgery, vol. 23, no. 9, pp. 941-943, 2007.

[8] A. G. Y. Chiou, J. Bovet, and C. de Courten, "Management of corneal ectasia and cataract following photorefractive keratectomy," Journal of Cataract and Refractive Surgery, vol. 32, no. 4, pp. 679-680, 2006.

[9] A. Leccisotti, "Corneal ectasia after photorefractive keratectomy," Graefe's Archives for Clinical and Experimental Ophthalmology, vol. 245, no. 6, pp. 869-875, 2007.

[10] C. F. Lovisolo and J. F. Fleming, "Intracorneal ring segments for iatrogenic keratectasia after laser in situ keratomileusis or photorefractive keratectomy," Journal of Refractive Surgery, vol. 18, no. 5, pp. 535-541, 2002.

[11] S. P. Holland, S. Srivannaboon, and D. Z. Reinstein, "Avoiding serious corneal complications of laser assisted in situ keratomileusis and photorefractive keratectomy," Ophthalmology, vol. 107, no. 4, pp. 640-652, 2000.

[12] J. B. Randleman, A. I. Caster, C. S. Banning, and R. D. Stulting, "Corneal ectasia after photorefractive keratectomy," Journal of Cataract and Refractive Surgery, vol. 32, no. 8, pp. 1395-1398, 2006.

[13] J. B. Randleman, M. Woodward, M. J. Lynn, and R. D. Stulting, "Risk assessment for ectasia after corneal refractive surgery," Ophthalmology, vol. 115, no. 1, 2008.

[14] J. B. Randleman, W. B. Trattler, and R. D. Stulting, "Validation of the ectasia risk score system for preoperative laser in situ keratomileusis screening," American Journal of Ophthalmology, vol. 145, no. 5, 2008.

[15] M. R. Santhiago, D. Smadja, B. F. Gomes et al., “Association between the percent tissue altered and post-laser in situ keratomileusis ectasia in eyes with normal preoperative topography," American Journal of Ophthalmology, vol. 158, no. 1, article e1, pp. 87-95, 2014.

[16] M. R. Santhiago, D. Smadja, S. E. Wilson, R. R. Krueger, M. L. R. Monteiro, and J. B. Randleman, "Role of percent tissue altered on ectasia after LASIK in eyes with suspicious topography," Journal of Refractive Surgery, vol. 31, no. 4, pp. 258-265, 2015.

[17] N. S. Jabbur, K. Sakatani, and T. P. O'Brien, "Survey of complications and recommendations for management in dissatisfied patients seeking a consultation after refractive 
surgery," Journal of Cataract and Refractive Surgery, vol. 30, no. 9, pp. 1867-1874, 2004.

[18] M. A. Woodward, J. B. Randleman, B. Russell, M. J. Lynn, M. A. Ward, and R. D. Stulting, "Visual rehabilitation and outcomes for ectasia after corneal refractive surgery," Journal of Cataract and Refractive Surgery, vol. 34, no. 3, pp. 383388, 2008.

[19] L. Torquetti and P. Ferrara, "Intrastromal corneal ring segment implantation for ectasia after refractive surgery," Journal of Cataract and Refractive Surgery, vol. 36, no. 6, pp. 986-990, 2010.

[20] O. Richoz, N. Mavrakanas, B. Pajic, and F. Hafezi, "Corneal collagen cross-linking for ectasia after LASIK and photorefractive keratectomy: long-term results," Ophthalmology, vol. 120, no. 7, pp. 1354-1359, 2013. 


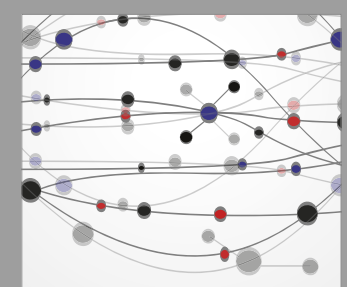

The Scientific World Journal
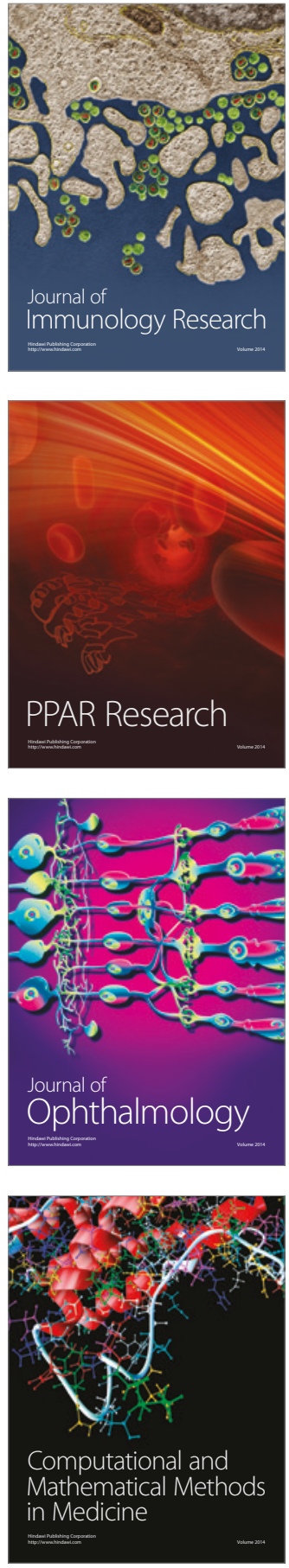

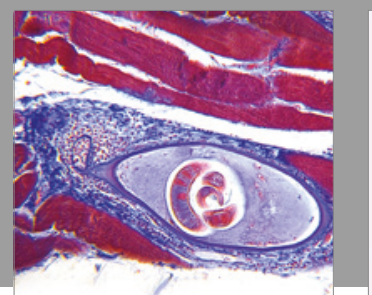

Gastroenterology Research and Practice
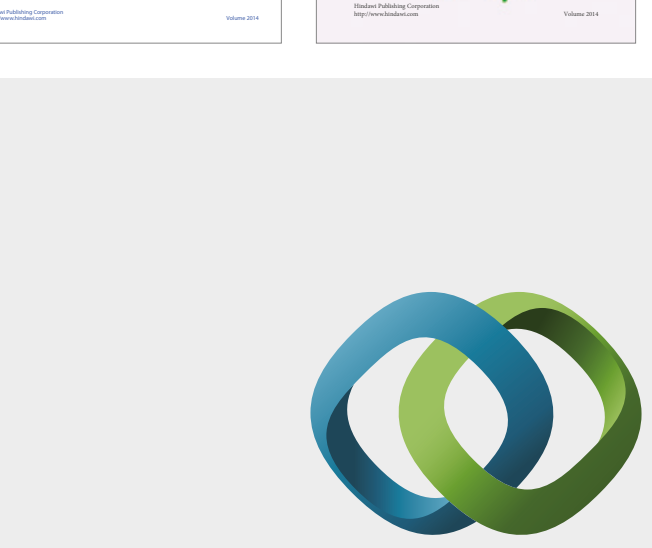

\section{Hindawi}

Submit your manuscripts at

https://www.hindawi.com
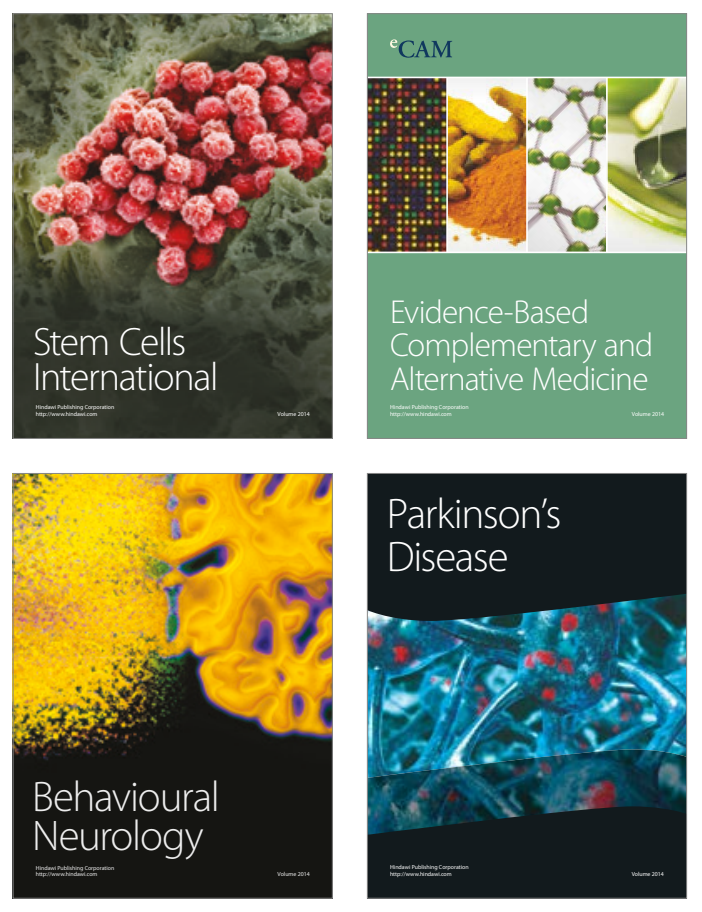
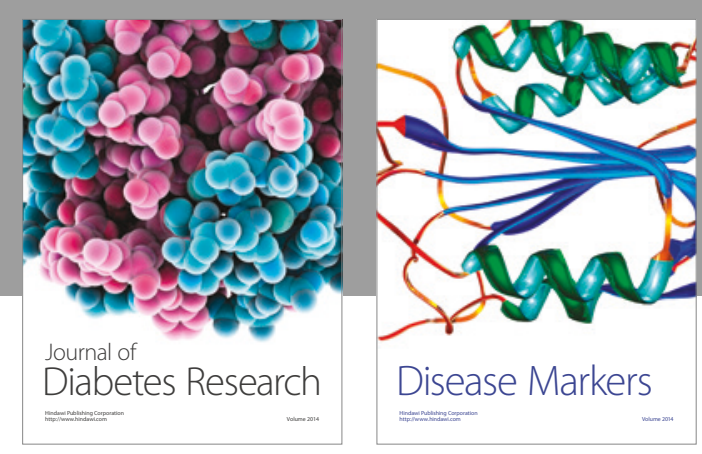

Disease Markers
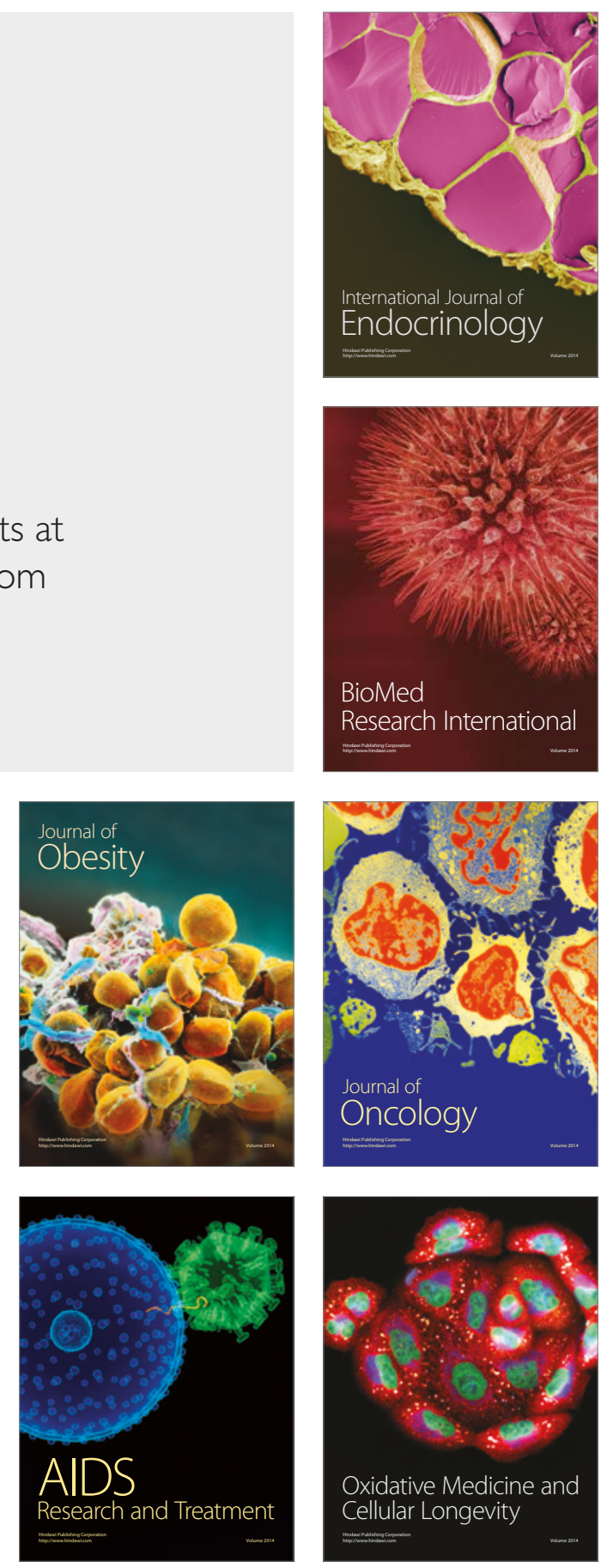